\title{
The performance of power and citizenship: David Cameron meets the people
}

Peter Lunt

School of Media, Communication and Sociology

University of Leicester, UK

P1108@1e.ac.uk

\begin{abstract}
How do citizens respond to and engage the performance of political power in the context of mainstream media? Through an analysis of two television programmes aired during the UK Brexit referendum campaign of 2016 a picture emerges of citizenship as the performative disruption of the performance of power. In the programmes the then UK Prime Minister, David Cameron, met members of the public for a mediated discussion of key issues in the Brexit referendum. Their interactions are analysed here as a confrontation between the performance of citizenship and power reflecting activist modalities of disruptive citizenship played out in the television studio. The article ends with reflections on questions about political agency as individualistic forms of disruptive political autonomy.
\end{abstract}

Keywords: political discourse; debate; civility; autonomy; performance

\section{Introduction}

In this article I examine the mediated juxtaposition and interrelation of the performance of power and citizenship in the context of two television programmes aired during the UK Brexit referendum campaign of 2016. The Prime Minister of the day, David Cameron, head of the campaign to remain in the European Union (EU), appeared on the shows, one at the launch of the campaign and one just days before the actual referendum. The shows were adaptions of the popular BBC current affairs panel discussion programme Question Time on which Cameron fielded questions from members of the public moderated by a programme host. In the first programme he was also interviewed by a political journalist in front of the television audience before taking questions.

There are several reasons why these shows are significant in relation to the intersection of political communication and the theme of this special issue, 'Citizenship and performance'. First, as popular culture, the programmes are part of the diversity of forms of political communication ranging from set piece party political broadcasts, political interviews, televised 
debates, talk shows and appearances by politicians on current affairs and popular daytime television programmes (Craig, 2016). Second, the mediated engagement between the Prime Minister and members of the public raises questions about the role of the media in public engagement that crosses boundaries between public discourse and politics. Third, as relatively unscripted public exchanges these engagements are performative as individuals, organizations, and parties moved "instinctively" to hook their actions into the background culture in a lively and compelling manner, working to create an impression of sincerity and authenticity rather than one of calculation and artificiality, to achieve verisimilitude' (Alexander et al., 2006: 1). The analysis illustrates that the performance of power by the Prime Minister was a construction of personal authenticity and political authority, and that the performance of citizenship by lay participants was as a disruption of the performance of power in the form of individualized dissent (Ruiz, 2014; 2016). This article provides an analysis of the two television programmes drawing on dramaturgy (Goffman, 1959) and performance studies followed by an analysis of the genealogy of both the performance of power and citizenship. The article ends with a discussion of the meaning and modality of the performance of citizenship as a subjectivity constructed as autonomy.

The Brexit referendum was a major political event that stood in a complex relation to traditional party political affiliation and engaged the public in a relatively open debate between sides representing the answer to a single question: whether to remain in the EU or to leave. Cameron, it has been widely acknowledged, as an ex-public relations man, was a consummate political performer across a range of media contexts (Craig, 2016). In a similar way to former US President Barack Obama, he had developed a style of political leadership that sought to overcome the excesses of spin and media management characteristic of the Clinton and Blair years (Craig, 2016). Until the EU referendum campaign, Cameron appeared as a highly skilled media performer accomplished at managing a variety of communication contexts such as press conferences, interrogative interviews with political journalists and set piece speeches such as the annual party conference. He was equally at home meeting the people in mediated town hall meetings or sitting on the sofa of current affairs television shows as he was when debating in the Chamber of the House of Commons. Craig (2016) argues that such multiply skilled performances across varied communication genres and contexts aims to manage, if not resolve, tensions between authenticity and performance, between the public politician and the private individual, between factual broadcasting and entertainment, and between legitimacy based on expertise and public popularity. Such a leadership style also aims to avoid or overcome the public cynicism that potentially results from the visibility of techniques of media management 
and spin that draws attention to the strategies of political communication rather than substantive claims and policy commitments (Capella and Jamieson, 1997).

Two television programmes were aired on free-to-air channels during the Brexit campaign in which Cameron came face to face with members of the public. The programmes were an extension of a series of similar encounters with members of the public that he made during his time as Prime Minister of a coalition government between his Conservative Party and the Liberal Party from 2010 to 2015. These 'meetings', called PM Direct, were made available on YouTube supported by transcripts available on the website of the Prime Minister's office, and were held in workplaces (e.g. Caterpillar, EasyJet and Rolls Royce). In these contexts, Cameron stood, often shirt-sleeved, amongst the employees or members who were seated at floor level between him and a single fixed camera and on a bank of chairs behind him. This production format created a space in which Cameron was framed by the audience as he delivered intense, short statements of the key points of his campaign agenda in response to questions from members of the audience. Unlike similar examples of political discussion programmes, the shows were unmoderated and Cameron managed the questions from the floor as well as being the only 'guest' on the show. An important feature of such encounters was that members of the audience were restricted to asking questions and there were no follow-up or supplementary questions. This lack of interactivity allowed Cameron the opportunity to treat questions as cues, to which he responded by delivering well-rehearsed statements of his policies or campaign agenda.

The Conservative Party adapted the PM Direct format for the 2015 General Election campaign. The context moved from workplace meetings to spaces in which greater control could be exercised over access and the production format of the events, and in which the audience acted as cheerleaders creating an excited emotional climate as Cameron pronounced. However, these occasions were constructed to create the impression of being public meetings. There is a long tradition in UK parliamentary election campaigns in which candidates hold public meetings in their constituencies in which they meet members of the public and address their questions and concerns. Such occasions are often robust and boisterous exchanges in which political discourse meets vernacular, committed expressions of politics. In contrast, in the versions of PM Direct aired during the 2015 General Election campaigns, another feature of the shows was the generation of the emotional climate of an election rally in which the 'audience' reacted positively and emotionally; Cameron was fired up and the audience was fired up. This was a simulation of the traditional campaign stump, but as a highly controlled and disciplined occasion in which enthusiastic party members created a sense of spontaneity 
as a background to Cameron's mini speeches. The Conservative Party won an unexpected majority in the 2015 General Election and one of the election promises had been to hold a referendum on Britain's membership of the EU that led to the referendum in 2016 when the two programmes analysed here were broadcast.

\section{Background to the EU referendum}

In a political campaign, notwithstanding the increasing importance of digital communication technologies, television remains a key site for performative embedding of campaign messages and engagement with national audiences. The communication styles of political leaders have adapted to make use of the diverse forms and contexts of communication balanced by disciplined campaigning and media management strategies. In the three weeks of Brexit campaigning between 2 and 22 June 2016, 15 mainstream television programmes were aired across several genres. These included political interviews conducted by well-known journalists, debates between leading representatives of the Remain and Leave campaigns, audience discussion programmes with members of the public and the programmes examined here, variants of Question Time in which key campaigners faced questions from members of the public. The BBC played a central role in staging 10 of the 15 television programmes during the campaign; ITV held three events, Sky News two and Channel 4 one. Recent commentators (Chadwick, 2013; Craig, 2016) have suggested that after a period of hyperbole about digital campaigning there is growing recognition that television is finding its place in contemporary campaigns, partly through innovations in programme forms and partly by complementing and intersecting with digital and social media campaigns.

In the UK a referendum once triggered by an Act of Parliament is managed not by government or political parties but by campaign groups that are chosen by the Electoral Commission to act as the official voice of the two campaigns representing the two sides of the referendum decision - in this case, Remain or Leave the EU. Bids are invited by groups that wish to represent each side of the referendum and the two groups chosen attract public campaign funds. The campaign for Remain was modelled on the Conservative Party campaign of the 2015 General Election. Having governed as part of a coalition with the Liberal Democrats since 2010, the Conservatives won an unexpected parliamentary majority in 2015. The results recorded increased support for both Conservatives and Labour, the Liberal vote collapsed and notably, there was a dramatic increase in nationalist votes for both the Scottish National Party (SNP) and the UK Independence Party (UKIP). The Daily Telegraph offered 
an insightful analysis of the successful Conservative election campaign organized by Lynton Crosby that demanded discipline from members of the Conservative Party, a campaign agenda that focused on economic policy, negative campaigning against their main rivals - Labour and the Liberal Democrats - focused on the party leaders (Ed Miliband and Nick Clegg), and David Cameron fronting the campaign in presidential style (Swinford, 2015).

The deployment of Cameron 'front and centre' formed a key part of the Remain campaign strategy as it had in the 2015 Conservative General Election campaign. This was partly justified by his high opinion poll ratings with 41 per cent approval during this period (Boffey, 2015), although these were moderated by perceptions of Cameron as uncommitted and unemotional, and by negative reactions to his upper-class social background. Craig (2016) discusses the strategy adopted to overcome these public perceptions of deploying Cameron's high-level media skills to make a direct appeal to the broader electorate. For example, Cameron handled interviews such as that by the BBC's political journalist Andrew Marr by skilfully challenging the host's framing of Conservative policy, answering only the questions he wanted to answer and refusing to be drawn into areas that might be problematic (Craig, 2016). The challenge facing Cameron and his advisors was to find ways of bringing his undoubted rhetorical and presentational skills into contact with a broader public to popularize his leadership. Consequently, skilful performance in political interviews was supplemented by a mixed communication strategy that kept Cameron in the public eye and aimed to soften his public image and spread his popular appeal.

\section{The television programmes}

\section{Sky News}

Cameron kickstarted the Remain campaign with an appearance on a Sky News special programme on 2 June 2016. The show began with an interview conducted by Faisal Islam, a political journalist, in front of a live television audience followed by a moderated Q\&A session with members of the studio audience hosted by Sky newsreader and presenter, Kay Burley. Islam opened his questioning by asking Cameron to stick to the facts about migration and to outline the figures for net migration during his leadership. This was challenging ground for Cameron because he had made a feature of his critique of the Brexit campaign by stating that it was based on false claims, anticipating subsequent debates about fake news and post-truth political discourse, and here he was being asked about the failure of his government to meet promises made in the General Election campaign to reduce migration to tens of thousands a 
year. Cameron gave a straight answer by admitting that 600,000 more people had entered the UK than had moved to other countries since he had come to power. When pressed as to whether he had broken a manifesto promise, he provided an intriguing justification by shifting the ground from a manifesto 'promise' to an 'ambition', suggesting that the relatively better performance of the UK economy during his period of office compared to Continental Europe had led to the creation of many new jobs that had attracted workers from abroad. A strategic advantage of this answer is that it shifted the focus on to Cameron's central campaigning agenda, the economic benefits of EU membership and the risks of leaving. He argued that the target "remains the right ambition for Britain" and that trying to cut immigration by leaving the EU and pulling out of the single market would be "madness" because of the economic damage it would cause. A number of further questions followed from Islam, most significantly challenging Cameron's references to the First World War to illustrate the potential security dangers of Brexit, which Islam suggested was an example of "fearmongering".

After further questions that were less challenging, the show changed gear (and genre), morphing into a mediated popular press conference or political talk show (Craig, 2016). Burley moderated the Q\&A session between members of the audience and Cameron. This combination of production formats was a challenge as the robust exchange with a professional journalist was followed immediately by a context that required softer skills to engage members of the public. What became immediately apparent was that Cameron continued with his strategy from PM Direct of treating questions as triggers or cues for campaign sound bites or as an expression of concern or lack of understanding of social or political issues. He saw his role as combining the provision of public information and a therapeutic alleviation of public fears and concerns. Rather than seeing indignation about the EU as an expression of substantial political critique addressing substantive political questions, his stance was that it reflected ignorance and anxiety. For example, one participant, identified as a businessman, asked Cameron to reflect on the "personal damage the scaremongering has done to your legacy." Cameron appealed to personal authenticity in the shape of his core political commitments: "I don't accept it is scaremongering. I am genuinely worried about Britain leaving the single market." He then linked his campaign focus on the economic risks of leaving the EU to his political authority: "Frankly, I think the job of the prime minister is to warn about potential dangers as well as to talk about the upsides and the opportunities there are by being a member of this organization." In addition, Cameron emphasized his reliance on and trust in a variety of experts who supported the claim that leaving the EU would be to the economic detriment of the UK and linking this to his political authority: "But if I didn't listen to the IMF, to the OECD, to the TUC, to the 
CBI, to the governor of the Bank of England - if I didn't listen to any of these people, I would not be doing my job and I would not be serving this country." As the campaign unfolded, Brexit campaigners were able to characterize such claims to authority as representing the interests of the great and the good: in other words, the establishment. Aversion to and criticism of the establishment is a key plank of populist political discourse (Jagers and Walgrave, 2007), which Cameron opened himself up to by invoking a consensus of expertise in favour of Remain.

Another questioner expressed concerns that during the Brexit campaign the Prime Minister shared a platform with the Mayor of London who he had strongly opposed as the Labour candidate in the mayoral election of the previous year. Criticizing the Mayor's apparent support or legitimation of terrorist groups, Cameron responded:

We had a lively election campaign in London, I didn't think it was the right choice some of the people he shared a platform with. The right thing for the PM to do is to work together. Sadiq and I disagree about many things; we'll try and work together and on this issue of Europe we agree. We buried our disagreements and appeared on a platform.

From Cameron's perspective, the contingencies of a referendum necessarily realigned politics across party lines and, as leader of the Conservative Party and Prime Minister, he would now find himself opposing the arguments and positions of some of his own party colleagues and working for the Remain campaign, which included many liberal or left-leaning organizations, public figures, and politicians. From the perspective of members of the public, however, the dissociation of Cameron from his role as leader of the Conservative Party and Prime Minister was not taken lightly. For example, one participant suggested the referendum was a vote of confidence in the government and in Cameron himself. Intriguingly, some political commentators ridiculed participants for such questions, but the difficulty of separating political commitments and allegiances from the question of membership of the EU was and remains non-trivial.

The limits of Cameron's communication strategy on this programme were well illustrated by his exchange with a literature student on the Sky News programme. The student, identified as Soraya Bouazzaoui, stated her concerns: "The entire campaign was nothing but scaremongering; no valid facts; no pros and cons and that everything I've seen makes voting into the EU look worse." The campaign, in other words, was high on persuasion and low on fact and argument, and significantly, this intelligent, informed, articulate member of the public was thinking of the referendum as a choice between 'voting in' and 'voting out'. Referenda are, however, usually deployed following parliamentary agreement on legislation that has 
significant constitutional implications, which is then put to the public for their assent. Cameron's original strategy was to negotiate significant changes to the UK's position in Europe, to get parliamentary approval for the changes, and then to put these new conditions to a referendum. In this scenario, the question put to the public would have been to ask them whether they agreed or disagreed with the new conditions for UK membership of the EU. However, Cameron was only able to negotiate adjustments to the UK's conditions of membership and, in this context, the referendum was drafted as an in/out vote giving equal weight to both sides and triggering more existential questions about membership of the EU. However, as is evident in Cameron's performance on this show, the Remain campaign avoided substantive political questions of migration and sovereignty to focus on economic policy.

Having expressed her concerns about the conduct of the Brexit campaigns, Bouazzaoui put her substantive question about the reassurances that Cameron had repeatedly made that remaining in the EU would make the UK safer in response to terrorist threats. Referring to concerns raised by Middle East states about Turkey's relations to and perceived support for terrorist groups, she questioned whether being in the EU meant that there were no risks in foreign policy. Cameron's response was characteristic, saying that he would address the two issues that Bouazzaoui had raised:

First, the positive case for staying. I think there is a positive case. I think we'll be better off as a country, with more jobs. I think we'll keep our country moving forward, we'll get things done in the world, whether it's tackling climate change or indeed standing up to Islamic terrorism ... and also, we'll be safer; strength in numbers.

This is a graphic illustration of Cameron's approach to questions from members of the public as a cue to deliver his campaign messages. However, the question was a legitimate and serious one, and Cameron's response clearly frustrated Bouazzaoui, who interrupted him:

That's not answering my question. Let me finish now, because I've seen you interrupt many people before. Let me finish. I'm an English Literature student, I know waffling when I see it, OK. I'm sorry, but you're not answering my question - how can you reassure people who want to vote out that we are safe from extremism when we are willing to work with a government like Turkey who want to be part of the EU when they are under heavy accusation?

Cameron's discomfort was evident and he tried to get back on track by saying that he had "got it" and addressed the question of Turkey's potential accession to the EU:

There is no prospect of Turkey joining the EU in decades. They applied in 1987, they have to complete 35 chapters. One has been completed so far. At this rate they will join 
in the year 3000. There are lots of reasons to vote one way or vote the other way. Turkey is not going to join the EU any time soon, every country, every parliament, has a veto. There are lots of things to worry about in this referendum campaign. I absolutely think that is not a prospect, it's not going to happen.

This exchange illustrates a number of aspects of the interaction between the performance of power and of citizenship in this programme. It demonstrates Cameron's strategy of taking questions as cues to which he responds with rehearsed campaign speeches. The passage also demonstrates that an important aspect of the performance of citizenship in this context is refusing the subject position of the audience to Cameron's pronouncements, to bring power to account by insisting on the relevance of answers, and disrupting the performance of power. Cameron's strategy of treating questions as expressions of concern that he takes as needing reassurance, information or contradiction leaves this participant, members of the audience, and by extension, the public, frustrated.

The programme demonstrated that the public were not in agreement with the Remain campaign's focus on the economic consequences of leaving the EU, and that a combination of substantive political questions related to migration, the legal framework of the EU, sovereignty, the impact of migration on public services and the efficacy of the government's austerity policies were all implicated in deciding how to vote in the referendum. Furthermore, Cameron's deflection of questions and his skilled practice of turning to his own agenda raised serious questions about both his claims to authenticity and political authority, on which his enviable popularity ratings had been based up to this point.

Press reaction to the programme was ambivalent. There was recognition that Cameron had got his agenda across despite the distraction of a hostile interview and having to manage the relationship with members of the public. In contrast, there was an acknowledgement that the interactions with members of the public were less convincing and seemed to illustrate a gap between the campaign agenda and public concerns. Interestingly this did not split neatly along the political affiliation of the papers - for example, Michael Deacon, writing in The Telegraph: 'The studio audience didn't think much of him, and he knew it. It was no disaster. But if you wondered why Mr Cameron didn’t fancy a proper debate: now you know' (Deacon, 2016).

\section{The BBC}

Shortly before the EU referendum Cameron appeared on a BBC programme to meet the people in an adaptation of the Question Time format, moderated by resident host David Dimbleby. 
This version of the programme differed in significant ways from the standard version of the show on which members of the studio audience are selected by the host, guided by the production team, to ask questions to a panel representing the main political parties plus celebrity guests. In the programme commissioned for the referendum, there was no panel and instead, David Cameron fielded all the questions

The producers and the host had learned from the Sky News programme and dealt with Cameron's tendency to not answer questions and shift topic onto his campaign agenda by clustering questions thematically. Consequently, although Cameron shifted topic in response to the questions, he found himself back on the same ground in the next question. The effect of this was exacerbated by the programme format which was unlike in the panel version of the programme in which different members of the panel voice alternative responses to audience questions, and to contest these among each other before the host turns back to the audience for supplementary questions and comments. In contrast, in this version of the programme one question to the Prime Minister was rapidly followed by another.

The first cluster of questions addressed the impact on the political culture of the Brexit campaign asking, for example, if it had "soured the political climate in the UK" by amplifying antagonisms. In response, Cameron attempted to draw a distinction between political commitment, passion and aggression, arguing that the committed use of reason, argument and rhetoric is essential to politics. He then invited the audience to contemplate what distinguishes reasonable/appropriate from unreasonable/inappropriate arguments and sentiments in political discourse and public debate. In this he positioned himself as on the 'right' side of these oppositions, claiming that his politics combined authentic personal commitment with political authority backed by arguments and claims backed by evidence. His opponents, by implication, were represented as political opportunists prepared to say anything to win, and consequently lacking both personal authenticity and political authority (Craig, 2016).

These reflections on civility in public and political discourse are all very interesting, but Cameron sidestepped the point that the questions were addressed to the conduct of his campaign as much as to the Brexit campaign and to the use of negative campaigning to discredit opponents. Nevertheless, Cameron pressed ahead, aiming to justify the comparison between himself and his political opponents. He focused on Nigel Farage, leader of the populist UKIP and a key figure in the campaign to leave the EU, although not part of the official 'Leave' group. Cameron referred to a Brexit campaign poster by UKIP that used a photograph of refugees crossing the border into Bosnia-Herzegovina with the headline 'Breaking Point'. He argued that Farage was "wrong in fact and wrong in motivation", and that the aim of Brexit 
campaigners was an "attempt to frighten and divide people." In the campaign, Brexit campaigners, particularly Boris Johnson, were able to turn this argument against Cameron by pointing to inconsistencies in his position on Europe, thereby challenging the authenticity of his position and characterizing his focus on the potential economic ills of leaving the EU as 'project fear'. At this point, the host intervened to ask, "Has your side been guilty of that?" articulating a commitment to impartiality as a moderator of the broader public debate. The theme continued including a question that challenged Cameron on the 'Brexit budget' prepared by the Chancellor to demonstrate the effects of leaving Europe on taxation and public spending. Cameron's reply suggested that his concerns were authentic, expressing his "genuine concern for the economic impact of leaving the EU" and citing, once more, the support of independent experts.

Following the exchange on the conduct of the campaigns was a series of questions and answers on Cameron's own future: would he resign if the country voted to leave? Would he call a general election if the vote was to leave the EU? These questions reflected the central role that Cameron played in the campaign, and although he tried to argue that the campaign was not about him, he shifted to his main agenda that we should remain for the sake of the economy, jobs, safety, security, and because being part of Europe strengthened the UK: "It comes down to a question of the economy and we need to work together - to grow the economy and beat terrorists."

How did Cameron find himself in such a difficult, compromised performative context? In the language of the history of the present (Foucault, 1977, 1984; Garland, 2014), a line can be traced back to his previous 'meetings' with members of the public in PM Direct allied to a leadership style that aimed to combine personal authenticity with political authority, and a disciplined approach to campaigning that included a presidential style with Cameron at the centre, negative campaigning against rivals and a focus on economic policy. The field of emergence for this configuration of leadership and campaigning styles was partly due the demands of the UK coalition government of Conservative and Liberal parties between 2010 and 2015 that demanded efforts at public communication as policies did not always clearly follow party lines. During this time there was also increasing public support for nationalist and populist parties that required renewed forms of popular communication from established political parties. However, the PM Direct events did not create a stage that afforded the opportunity for authenticated engagement with members of the public but instead, were 'managed shows' (Thompson, 1995) in which Cameron and his team selected the places and audiences and set the rules of interaction. In contrast, as we have seen, the two television shows 
in which he met the people in the Brexit campaign were managed by the broadcasters and gave opportunities for the performance of disruptive citizenship. Instead of a controlled context that afforded the illusion of public engagement while allowing Cameron to deliver his campaign message, he found himself involved in a contested performative space. So how did members of the public find themselves occupying space in the television studio and challenging the performance of power?

The difficulties experienced by Cameron and the opportunity afforded to citizens was a function of the production format of the programme as a mise en scène for the performances of power and citizenship. The two programmes included significant variations on the Question Time format, a popular political panel talk show in which guest members of the public put topical social and political questions to a panel. Question Time is a microcosm of the role of factual programming in public service broadcasting assuming a politics of pluralism, represented by the different panel members who stand for the main political parties as competitive interest groups and, therefore, representing a particular idea of public accountability understood as a fair and balanced representation of the views of different competing interests in the political sphere (Karppinen, 2007). The transformation of the programme format in which the panel was replaced by Cameron represents a shift from the idea of communication of politics in which different positions are put in front of the public (democratic pluralism) with commentary from expertise (elite democracy), to the appropriation of public broadcasting as a vehicle for a political campaign. In the traditional formulation, the responsibility of public service broadcasting is to create contexts in which competing interests have equal opportunities to state their arguments and to provide an expert commentary on those views. In contrast, placing Cameron in the place of the panel made the Prime Minister the single recipient of questions, transforming the programme into a popular version of the press conference in comparison to the panel format adopted in Question Time, which constituted a debate between different political positions.

Episodes of Question Time usually proceed in a sequence in which the host invites a question from the studio audience and then asks panel members to answer. In this sense, Question Time is characterized by contestation, argument and often conflict between panel members as they debate alternative answers to the questions under the direction and scrutiny of the programme host. The host then goes back to the audience for supplementary questions and reactions, and finally the person who asked the question gives their reactions and reflections. In contrast, Cameron's previous mediated town hall PM Direct 'meetings' were a pale reflection of the dynamics of Question Time. There was no variety of responses to 
questions, just Cameron's, and no display of divergent views or contestation in front of the audience. The rhythm of exchanges and arguments and the emotional flow of the programmes were altered considerably by these changes, becoming a series of Q\&A rather than a question followed by a robust exchange and opportunity for further audience engagement. In terms of the flow of emotions, instead of a dispersed exchange of feelings, views and political commitments, the direction of sentiment was focused on Cameron.

\section{Reflections and conclusions}

How are we to think about the performance of citizenship in these programmes and the implications for understanding political subjectivity and agency? These disruptive encounters appear to be the work of individuals asserting their rights to visibility in public and to challenge the performance of power. In terms of asserting communicative rights participants communicate in a performative practice similar to Isin and Ruppert's (2015) account of digital citizenship as rights claiming practice. However, these appear to be political acts undertaken by individuals expressing their autonomy by occupying a space (mainstream television studios) in which the performance of power is made visible and realized through the interaction between the performance of power and citizenship. The lay participants on these programmes are not there to press individual claims and nor are they there to represent an emerging collective or connective (Bennett and Segerberg, 2012); they are there as citizens, as individuals aiming to have their say, bring power to account and disrupt attempts to persuade. This is a form of what Dayan (2009) calls 'monstration' and takes up his argument that as television broadcasting converges with digital culture it can be understood by analogy to the bulletin board on which individual citizens post their messages to the public.

Such performances of citizenship are agentic, skilful deployments of material and symbolic resources in staged interactions articulated as individualized forms of dissent (Ruiz, 2014, 2016). The television discussion programmes in which Cameron met the people reflect 'the ways in which citizens - from protestors in Occupy movements ... to participants [in] street performances reclaim public space as a place to play out, both expressively and deliberatively, struggles for recognition and new political subjectivities' (Rovisco and Ong, 2016: 3). In this sense although appearing on television their actions reflected recent activism and protest in what Gerbaudo (2016) terms 'the digital popular'. The invasion of the television studio and programme space reflects the transgressions of space by the Occupy movement. This is an incursion into mainstream media culture deploying some of the tactics of new protest 
movements in the name of individual citizens. Along with the invasion of public spaces, new social movements experiment with radical forms of democracy by making use of the resources of digital media in reclaiming the square (Rovisco and Ong, 2016). In so doing, they engage with activities within the square that reflect conceptions of direct democracy and civic virtue (Dagger, 1997). Just as digital and social media provide social movements with new resources that ameliorate their lack of access to mainstream media resources so, here, performative disruption seeks to influence through visibility and public impact and by providing models of alternative political practices.

Perhaps what is at stake here is that the disruption of political communication and the occupation of the places of media production appear to express the position of individual citizens intervening in public communication and debate. Such activism appears to suggest a trajectory from personal concerns that are projected into the public sphere through performance as a social practice that inserts personal issues and commitments into mediated public life. There are other examples of a trajectory from personal commitment and action to political debate, such as when individuals protest about the environmental implications of global systems of production and distribution through individual and localized practices of consumer activism (Lekakis, 2013). One way to make sense of this is as a combination of political autonomy and democracy as a social practice (Gray, 2000). Or, following Dagger (1997), to argue that participants perform individualized dissent related to questions of public interest in civically virtuous expressions of individual political autonomy as:

... social actors, embedded in collective representations and working through symbolic and material means, implicitly orient towards others as if they were actors on a stage seeking identification with their experiences and understandings from their audiences. (Alexander et al., 2006: 2)

These programmes stage an encounter between performances of power and citizenship (Goffman, 1961), that instantiates the blurring of boundaries in contemporary political culture reflecting tropes of digital citizenship in their disruption of power (Isin and Rupert, 2015) and the digital popular as sites of occupation that engage new political subjectivities (Gerbaudo, 2016). In this article I have explored the way that these trends spill over into mainstream, linear media to disrupt the performance of power in a staged encounter by autonomous, individual political subjects (Gray, 2000). Traditional differentiations between the state and the body politic (Habermas, 1987), between questions of politics and values (Rawls, 1993), and between civil and uncivil discourses and actions (Mouffe, 2005), are all potentially blurred in the current conjuncture typified by the example of when Cameron met the people. 


\section{References}

Alexander JC, Giesen B and Mast JL (eds) (2006) Social Performance: Symbolic Action, Cultural Pragmatics, and Ritual. Cambridge: Cambridge University Press.

Bennett WL and Segerberg A (2013) The Logic of Connective Action. Cambridge: Cambridge University Press.

Boffey D (2015) David Cameron maintains high approval rating, despite Labour's poll lead. The Guardian, 15 February. Available www.theguardian.com/politics/2015/feb/14/opinium-poll-david-cameron-maintainsapproval-rating (accessed on 31 July 2018).

Capella JN and Jamieson KH (1997) Spiral of Cynicism: The Press and the Public Good. New York: Oxford University Press.

Chadwick A (2013) The Hybrid Media Systems: Politics and Power. Oxford: Oxford University Press.

Craig G (2016) Performing Politics. Cambridge: Polity Press.

Dagger R (1997) Civic Virtues: Rights, Citizenship, and Republican Liberalism. Oxford: Oxford University Press.

Dayan D (2009) Sharing and showing: Television as monstration. The Annals of the American Academy of Political and Social Science 625, The end of television? Its impact on the world (so far), September: 19-31.

Deacon M (2016) 'I know waffling when I see it!' David Cameron takes a Brexit roasting. The Telegraph, 2 June. Available at: www.telegraph.co.uk/news/2016/06/02/i-know-wafflingwhen-i-see-it-david-cameron-takes-a-brexit-roast/ (accessed on 31 July 2018).

Foucault M (1977) Discipline and Punish: The Birth of the Prison. New York: Pantheon.

Foucault M (1984) Nietzsche, genealogy, history. In: Rabinow P (ed) The Foucault Reader. New York: Pantheon. 76 - 100

Garland D (2014) What is a 'history of the present'? On Foucault's genealogies and their critical preconditions. Punishment \& Society 16(4): 365-384.

Gerbaudo P (2016) Occupying the digital-popular. In: Rovisco M and Ong J (eds) Taking the Square: Mediated Dissent and Occupations of Public Space. London: Rowman \& Littlefield, $37-54$.

Goffman E (1959) The Presentation of Self in Everyday Life. Hamondsworth: Penguin.

Goffman E (1961) Encounters: Two Studies in the Sociology of Interaction. New York: The Bob Merrell Company. 
Gray J (2000) Two Faces of Liberalism. Cambridge: Polity Press.

Habermas J (1987) The Theory of Communicative Action, Volume 2: Lifeworld and System: A Critique of Functionalist Reason. Cambridge: Polity Press.

Isin E and Ruppert E (2015) Being Digital Citizens. London: Rowman \& Littlefield.

Jagers J and Walgrave S (2007) Populism as political communication style: An empirical study of political parties' discourse in Belgium. European Journal of Political Research 46: 319345.

Karppinen K (2007) Against naïve pluralism in media politics: On the implications of the radical-pluralist approach to the public sphere. Media, Culture \& Society 29(3): 405-508.

Lekakis EJ (2013) Coffee Activism and the Politics of Fair Trade and Ethical Consumption in the Global North. London: Palgrave Macmillan.

Mouffe C (2005) On the Political. London: Sage.

Rovisco M and Ong J (eds) (2016) Taking the Square: Mediated Dissent and Occupations of Public Space. London: Rowman \& Littlefield.

Rawls J (1993) Political Liberalism. New York: Colombia University Press.

Ruiz P (2014) Articulating Dissent: Protest and the Public Sphere. London: Pluto.

Ruiz P (2016) Identity, place and politics: From picket lines to occupation. In: Rovisco M and Ong J (eds) Taking the Square: Mediated Dissent and Occupations of Public Space. London: Rowman \& Littlefield, 15 - 36.

Swinford S (2015) Election 2015: How David Cameron's Conservatives won. The Telegraph, 8 May. Available at: www.telegraph.co.uk/news/general-election-2015/11592230/Election2015-How-David-Camerons-Conservatives-won.html (accessed on 31 July 2018).

Thompson J (1995) The Media and Modernity: A Social Theory of the Media. Cambridge: Polity Press. 